\title{
Expression profiles of genes and enzymes related to ascorbic acid metabolism in fruits of Ziziphus jujuba Mill. 'Jinsixiaozao'
}

\author{
Yingying CHEN ${ }^{1 *}$, Zhihui ZHAO ${ }^{1 *}$, Jin ZHAO $(\bowtie)^{2}$, Mengjun LIU (ه) ${ }^{1}$ \\ 1 Research Center of Chinese Jujube, Agricultural University of Hebei, Baoding 071001, China \\ 2 College of Life Science, Agricultural University of Hebei, Baoding 071000, China
}

\begin{abstract}
The fruit of Chinese jujube (Ziziphus jujuba) possesses extremely high concentrations of ascorbic acid (AsA). The accumulation of AsA, the expression patterns of the nine genes related to AsA metabolism as well as the activities of five enzymes involved in AsA synthesis, oxidation and recycling were investigated during fruit development in Z. jujuba Mill. 'Jinsixiaozao'. The results showed that the high level of AsA accumulation in jujube fruit is due to a contribution from both AsA biosynthesis and AsA recycling. It is suggested that L-galactono-1,4lactone dehydrogenase, ascorbate peroxidase and monodehydro-ascorbate reductase are the crucial genes/ enzymes of jujube AsA synthesis, oxidization and recycling, respectively. These results provide useful new insights into the regulatory mechanisms of AsA accumulation in Chinese jujube.
\end{abstract}

Keywords Chinese jujube, ascorbic acid, metabolism, gene, enzyme

\section{Introduction}

Ascorbic acid (AsA), also named as ascorbate or vitamin $\mathrm{C}$, is an essential metabolite for both plants and animals. However, humans lack the ability to synthesize AsA, so plants are the major source of dietary AsA for humans. In plants, AsA is involved in expansion, division and enlargement of cells, promoting the formation of apical meristem, regulating flowering, fruit development and senescence and many other physiological processes ${ }^{[1-5]}$. It is also an effective radical scavenger that is able to interact with the reactive oxygen species ${ }^{[6]}$. In fruits, AsA

Received February 17, 2016; accepted April 9, 2016

Correspondences: zhaojinbd@126.com,1mj1234567@aliyun.com

${ }^{*}$ These authors contributed equally to the work concentration has become a key indicator for quality evaluation. The fruit of Chinese jujube (Ziziphus jujuba Mill.), one of the native and main fruit species of China, is an outstanding source of AsA. The AsA concentration of jujube fruit is a few dozen times that of other common fruit and even higher than kiwifruit ${ }^{[7]}$ and understanding the mechanism underlying the high accumulation of AsA in Chinese jujube is important.

At least four distinct pathways for AsA biosynthesis have been described in plants, including L-galactose (or Smirnoff pathway) ${ }^{[8]}$, L-glucose pathway ${ }^{[9]}$, galacturonic acid pathway ${ }^{[10]}$ and myo-inositol pathway ${ }^{[11]}$. Among the four pathways, the L-galactose pathway is thought to be the dominant one for AsA biosynthesis in many plants ${ }^{[12-15]}$. To date, significant efforts have been made to investigate AsA metabolism in various fruit species, such as kiwifruit ${ }^{[16]}$, apple ${ }^{[17]}$ and strawberry ${ }^{[18]}$, and the results suggest that AsA concentration in fruit can be modulated during fruit development.

We recently carried out a comparative genomic and transcriptomic study in Chinese jujube after de novo genome sequencing ${ }^{[19]}$ showed that the L-glucose pathway is the predominant AsA biosynthesis pathway in Chinese jujube, and the high vitamin $C$ concentration in jujube fruit can be attributed to high level expansion of the gene family involved in this biosynthesis pathway (as in sweet orange ${ }^{[20]}$ ) and higher expression of the genes involved in the recycling pathway (as in kiwi fruit ${ }^{[21]}$ ). However, the crucial genes involved in AsA accumulation and the mechanism modulating AsA concentration during fruit development in Chinese jujube are still unclear.

In this study, one of the most popular jujube cultivars 'Jinsixiaozao' was investigated. The AsA concentration, the expressions of nine related genes and the activities of five enzymes involved in AsA biosynthesis, oxidization and regeneration were systematically analyzed at five different fruit developmental stages. This study provides insights into the distinct AsA metabolism in Chinese 
jujube and will be helpful to further genetic engineering studies.

\section{Materials and methods}

\subsection{Plant material}

The fruit of Z. jujuba Mill. 'Jinsixiaozao' was sampled from the National Jujube Germplasm Resources Nursery (NJGRN) located in Taigu County, Shanxi Province, China. The samples were harvested at five fruit developmental stages, i.e., young fruit (stage I), pre-white ripening (stage II), white ripening (stage III), half-red ripening (stage IV) and full-red ripening (stage V). Three replicates (each treatment contains 10 fruits) were taken at each stage and the samples were immediately frozen in liquid nitrogen and stored at $-72^{\circ} \mathrm{C}$ for further analysis.

The fruit diameter and weight of 30 fruits at five stages was also measured by caliper and electronic balance, respectively. Fruit growth curves were drawn based on the mean values.

\subsection{Determination of AsA concentration with HPLC}

AsA was extracted in metaphosphoric acid ${ }^{[7]}$. Exactly $0.5 \mathrm{~g}$ fresh fruit was used to prepare $50 \mathrm{~mL}$ of AsA solution in $0.1 \%$ metaphosphoric acid. This was loaded onto a Reverse C18 column $(250 \mathrm{~mm} \times 4.6 \mathrm{~mm}$, I.D. $5 \mu \mathrm{m})$ and eluted at $1 \mathrm{~mL} \cdot \mathrm{min}^{-1}$ at $25^{\circ} \mathrm{C}$. The mobile phase was $0.02 \mathrm{~mol} \cdot \mathrm{L}^{-1}$ phosphate buffer solution. AsA was determined at $260 \mathrm{~nm}$. AsA concentrations were determined by standard curve and expressed as mg per $100 \mathrm{~g}$ FW. All samples were assayed three times and all operations were conducted in the dark in order to prevent AsA oxidation.

\subsection{Total RNA isolation and cDNA synthesis}

Isolation of total RNA was carried out as described in the improved CTAB method ${ }^{[22]}$. DNase I treatment was applied to remove contaminating genomic DNA. The quantity and quality of the RNA were verified by measuring the absorbance spectrum with NanoDrop N1000 spectrophotometer (NanoDrop Products, Wilmington, DE, USA) and were determined spectrophotometrically by measuring the OD260/280 and OD260/230. Firststrand cDNA was performed using the TransScript Firststrand cDNA synthesis SuperMix AT301 (TransGen Biotech, Beijing, China), according to the manufacturer's protocol.

\section{4 qRT-PCR analyses}

The gene $\mathrm{ZjH} 3$ was used as the internal control ${ }^{[23]}$. Gene- specific primers were designed from the coding sequences of other related genes using Primer Premier 5.0 software. qRT-PCR was performed on a Bio-Rad $\mathrm{iQ}^{\mathrm{TM}} 5$ using TransStart Top Green qPCR SuperMix AQ131, according to the manufacturer's instructions. Primer specificity was determined by RT-PCR and melting-curve analysis. The $25 \mu \mathrm{L}$ reaction system contains $12.5 \mu \mathrm{L}$ of $2 \times \mathrm{SYBR}$ Premix ExTaq ${ }^{\mathrm{TM}}, 0.5 \mu \mathrm{L}$ each of $10 \mu \mathrm{mol} \cdot \mathrm{L}^{-1}$ primers, $10.5 \mu \mathrm{L}$ dd $\mathrm{H}_{2} \mathrm{O}$ and $1 \mu \mathrm{L}$ diluted cDNA. The thermal profile for qRT-PCR was pre-incubated for $30 \mathrm{~s}$ at $95^{\circ} \mathrm{C}$, followed by 40 cycles of $5 \mathrm{~s}$ at $95^{\circ} \mathrm{C}, 10 \mathrm{~s}$ at $52^{\circ} \mathrm{C}$ and $10 \mathrm{~s}$ at $72^{\circ} \mathrm{C}$. Subsequently, a melting curve analysis was run for one cycle from 55 to $90^{\circ} \mathrm{C}$. Data from the individual runs were collated using the $2^{-\Delta \Delta C_{\mathrm{T}}}$ method ${ }^{[24]}$. Values for mean expression and standard deviation were calculated from the results of three independent experiments.

\subsection{Assay of enzyme activity}

The crude extraction of L-galactono-1,4-lactone dehydrogenase (GLDH) enzyme was prepared according to the published method with some modification ${ }^{[25]}$. A $1.0 \mathrm{~g}$ sample was homogenized in $10 \mathrm{~mL}$ of $0.1 \mathrm{~mol} \cdot \mathrm{L}^{-1}$ potassium phosphate buffer ( $\mathrm{pH}$ 7.4) containing $0.4 \mathrm{~mol} \cdot \mathrm{L}^{-1}$ sucrose, $10 \%(\mathrm{v} / \mathrm{v})$ glycerol, $0.1 \mathrm{mmol} \cdot \mathrm{L}^{-1}$ phenylmethanesulfonyl fluoride, $0.3 \%(\mathrm{v} / \mathrm{v})$ mercaptoethanol and $2 \%(\mathrm{w} / \mathrm{v})$ polyvinylpyrrolidone. The homogenate was centrifuged at $500 \mathrm{~g}$ for $20 \mathrm{~min}$ at $4^{\circ} \mathrm{C}$ to collect supernatant, and then the supernatant was centrifuged at $12000 \mathrm{~g}$ for $15 \mathrm{~min}$ at $4^{\circ} \mathrm{C}$. The resulting pellet was suspended in $3 \mathrm{~mL} 0.1 \mathrm{~mol} \cdot \mathrm{L}^{-1}$ phosphate buffer $(\mathrm{pH} 8.0)$ containing $5 \mathrm{mmol} \cdot \mathrm{L}^{-1}$ glutathione, $1 \mathrm{mmol} \cdot \mathrm{L}^{-1}$ EDTA and $10 \%(\mathrm{v} / \mathrm{v})$ glycerol and centrifuged again at $2000 \mathrm{~g}$ for $10 \mathrm{~min}$ at $2^{\circ} \mathrm{C}$. The supernatant containing crude mitochondrial protein was used to determine GLDH activity.

GLDH activity was assayed by following the reduction of cytochrome $\mathrm{c}$ at $550 \mathrm{~nm}$ at $25^{\circ} \mathrm{C}$. The reaction mixture $(1.5 \mathrm{~mL})$, containing $60 \mathrm{mmol} \cdot \mathrm{L}^{-1}$ cytochrome $\mathrm{c}$, $1 \mathrm{mmol} \cdot \mathrm{L}^{-1}$ sodium azide, $2.5 \mathrm{mmol} \cdot \mathrm{L}^{-1} \mathrm{~L}$-galactose, $0.1 \%(\mathrm{v} / \mathrm{v})$ Triton X-100 and $0.1 \mathrm{~mL}$ of the enzyme extract in the $50 \mathrm{mmol} \cdot \mathrm{L}^{-1}$ Tris- $\mathrm{HCl}(\mathrm{pH} 8.5)$, was pre-incubated at $27^{\circ} \mathrm{C}$ for $5 \mathrm{~min}$. Subsequently reduction of cytochrome c was monitored by the increase in absorption at $550 \mathrm{~nm}$. One unit of enzyme was defined as the reduction of $1 \mathrm{mmol} \cdot \mathrm{L}^{-1}$ cytochrome c per minute.

The crude extraction and determination of ascorbate oxidase (AO) followed the method of Esaka ${ }^{[26]}$ and dehydroascorbate reductase (DHAR), monodehydroascorbate reductase (MDHAR), ascorbate peroxidase (APX) previously published methods ${ }^{[26,27]}$.

Each treatment was replicated three times with each sample measured three times. Results were represented as the means and standard deviation. 


\section{Results}

3.1 Variation of ascorbic acid concentration during fruit development

AsA concentration in jujube fruit fluctuated between 600 and $800 \mathrm{mg}$ per $100 \mathrm{~g} \mathrm{FW}$ during fruit development (Fig. 1a) and there were major changes in the activities of metabolic enzymes (Fig. 1b). In the rapid fruit growth period, from young fruit stage to pre-white ripening stage (Fig. 1a), AsA concentration increased slowly and reached a peak before the white ripening stage. Then, AsA concentration decreased rapidly at later fruit development stages. After the half-red ripening stage, AsA concentra- tion showed a small increase, reaching $705 \mathrm{mg}$ per $100 \mathrm{~g}$ FW at the full-red ripening stage.

3.2 Expression profiles of genes involved in ascorbic acid metabolism

Nine genes related to $\mathrm{Vc}$ metabolic pathways were cloned and their expression studied (Fig. 2). Eight genes related to AsA metabolism were isolated by homologous gene cloning methods using the relevant data from the jujube genome, i.e., GDP-D-mannose pyrophosphorylase (ZjGMP, accession number KJ934995), GDP-mannose 3',5'-epimerase (ZjGME), GDP-L-galactose phosphorylase $(Z j G G P)$; L-galactose-1-P phosphatase (ZjGPP, accession

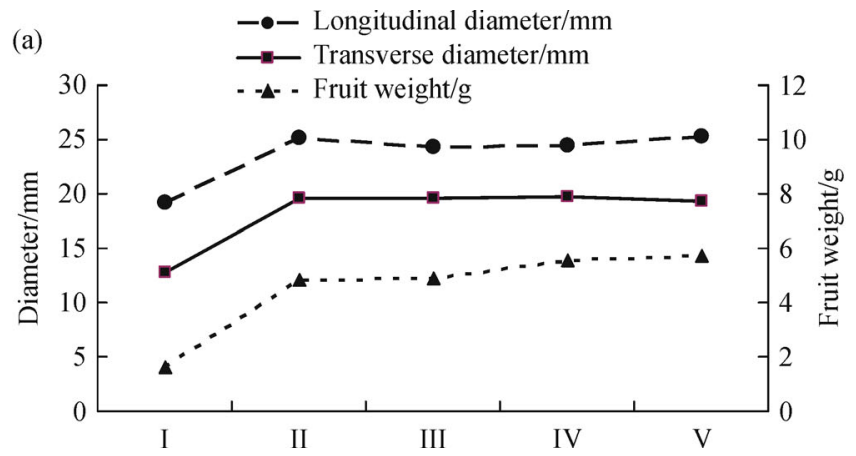

(b)

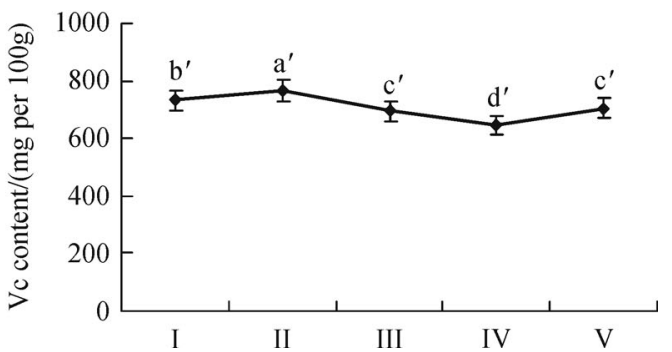

Fig. 1 Changes of fruit diameter and weight during fruit development (a) and ascorbic acid concentration of fruit during fruit development (b). a', b', $\mathrm{c}^{\prime}$ and d' mean the significant level at 5\%. I, young fruit stage; II, pre-white ripening stage; III, white ripening stage; $\mathrm{IV}$, half-red ripening stage; $\mathrm{V}$, full-red ripening stage.
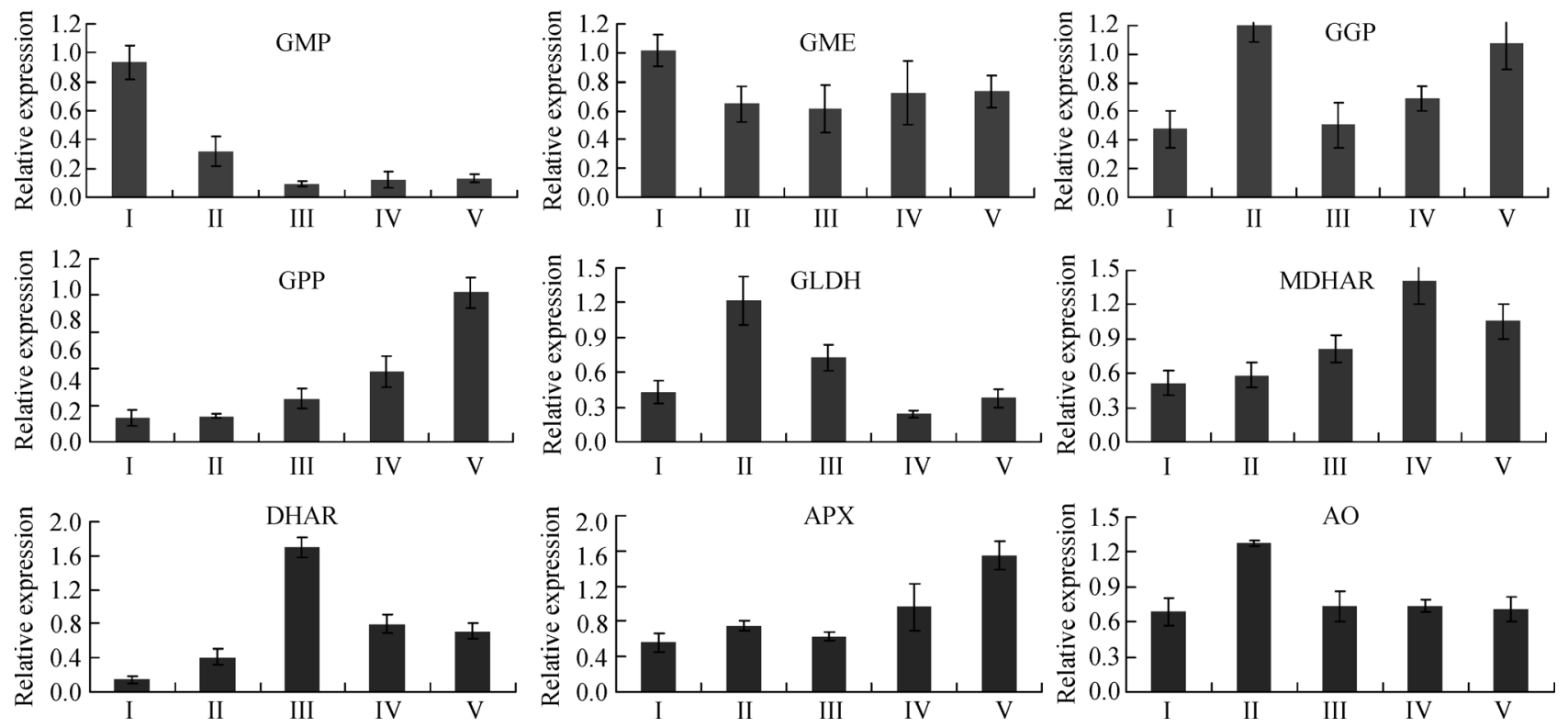

Fig. 2 Relative expressions of genes involved in AsA biosynthesis and recycling in jujube fruit. Enzymes studied were: GDP-Dmannose pyrophosphorylase (GMP), GDP-mannose 3',5'-epimerase (GME), GDP-L-galactose phosphorylase (GGP); L-galactose-1-P phosphatase (GPP), L-galactose dehydrogenase (GLDH), monodehydroascorbate reductase (MDHAR), dehydroascorbate reductase (DHAR), ascorbate peroxidase (APX), ascorbate oxidase (AO). I, young fruit stage; II, pre-white ripening stage; III, white ripening stage; $\mathrm{IV}$, half-red ripening stage; $\mathrm{V}$, full-red ripening stage. 
number KJ739593), L-galactose dehydrogenase $(\mathrm{Zj} G L D H)$, ascorbate oxidase $(\mathrm{ZjAO})$, dehydroascorbate reductase $(Z j D H A R)$, and monodehydroascorbate reductase (ZjMDHAR). These genes belong to three groups, synthetic genes (GMP, GME, GGP, GPP, GLDH), oxidic genes (MDHAR, DHAR) and recycling genes $(A P X, A O)$. Further analysis indicated that the amino acid sequences predicted from these genes possessed high homology with the respective sequences in other plants.

The expression of the above nine genes in flesh fruit were examined and all showed significant variations during fruit development. Among the five synthetic genes, only $G L D H$ showed an expression pattern similar to the variation in AsA concentration. Of the two recycling genes, the DHAR expression level showed a similar change to the AsA concentration, and MDHAR expression kept increasing during the whole fruit development period, which might help in maintaining the high level of AsA in jujube fruit. In the case of the two oxidic genes, the expression level of $A P X$ increased uniformly, while $A O$ expression remained stable except for a rise at the prewhite ripening stage. The resulting changes in AsA concentration were a consequence of interactions among synthetic, oxidic and recycling genes and their encoded enzymes. Among the nine genes, GLDH, DHAR, MDHAR, $A P X$ and $A O$ are more important for AsA accumulation in jujube fruit. In view of this, the enzymes of the five genes were chosen for further analysis of enzyme activities.

\subsection{Activity changes of five selected enzymes}

The enzyme activities of GLDH, MDHAR, DHAR, APX and AO during fruit development were analyzed by spectrophotometry (Table 1). The result showed that DHAR activity remained low, and the activities of the other four enzymes changed significantly. Of the four enzymes, GLDH activity showed a similar change to the AsA concentration whereas the activities of MDHAR, APX and AO were higher at the later stages. GLDH, MDHAR, APX and AO appeared to contribute to AsA accumulation, and the former three, i.e., one synthetic enzyme GLDH, one recycling enzyme MDHAR, and one oxidic enzyme APX, were more important.

\section{Discussion}

AsA concentrations in higher plants are controlled by a dynamic balance between biosynthesis, oxidation and recycling. AsA is not a stable metabolic product and can be oxidized to monodehydroascorbate (MDHA) and dehydroascorbate (DHA) by APX and AO. MDHA and DHA could also be enzymatically reduced to AsA by MDHAR and $\mathrm{DHAR}^{[25]}$. Recently, significant efforts have been devoted to investigating the regulation of ascorbate in fruits $^{[28-33]}$. The importance of MDHAR and DHAR in controlling AsA levels in plant tissues has been demonstrated in transgenic plants by overexpressing these two enzymes ${ }^{[25,34]}$. This is judged to have led to a huge increase of AsA concentrations through improving the rate of AsA recycling. In plants, whether AsA is in the reduced state, or DHA and MDHA in the oxidized states, both originate from the synthesis of AsA. In other words, AsA synthesis is the basis of its accumulation. Our research indicated that $G L D H / \mathrm{GLDH}$ might be the key gene/ enzyme of AsA synthesis in Chinese jujube. However, reduction of GLDH activity by RNA interference in tomato did not alter the L-ascorbate synthesis capacity in the transgenic plants ${ }^{[35]}$. Thus, further experimental work at the post-transcriptional and translational levels is required to understand the regulatory mechanisms of AsA synthesis in Chinese jujube and other plants.

Apart from synthesis, the recycling pathway also influences the accumulation of AsA. In the case when the recycling speed surpasses the oxidation speed, the difference causes the re-accumulation of AsA. Our results showed that the expression of MDHAR and the activity of MDHAR kept increasing during fruit development, while DHAR expression and its activity decreased uniformly or remained stable, indicating $M D H A R / \mathrm{MDHAR}$ is more important and may be the key regeneration gene/enzyme in AsA recycling of 'Jinsixiaozao'. Turning to AsA oxidization, in this study both the expression of $A P X$ and the activity of APX increased uniformly during fruit development, while $A O / \mathrm{AO}$ remained stable or relatively low, indicating $A O / \mathrm{AO}$ has a limited role in the reducing of AsA and $A P X / \mathrm{APX}$ should be considered the key oxidic gene/ enzyme in AsA metabolism of 'Jinsixiaozao'. It is worth

Table 1 Changes in the activity of five selected enzymes during jujube fruit development

$\mathrm{U} \cdot \mathrm{g}^{-1}$

\begin{tabular}{|c|c|c|c|c|c|}
\hline \multirow{2}{*}{ Enzyme } & \multicolumn{5}{|c|}{ Fruit development stage } \\
\hline & I & II & III & IV & $\mathrm{V}$ \\
\hline GLDH & $2.52^{\mathrm{b}}$ & $3.74^{\mathrm{a}}$ & $2.04^{\mathrm{c}}$ & $2.64^{\mathrm{b}}$ & $1.86^{\mathrm{c}}$ \\
\hline MDHAR & $1.46^{\mathrm{b}}$ & $1.62^{\mathrm{b}}$ & $2.26^{\mathrm{a}}$ & $2.50^{\mathrm{a}}$ & $2.38^{\mathrm{a}}$ \\
\hline DHAR & $0.82^{\mathrm{ab}}$ & $0.76^{\mathrm{b}}$ & $0.92^{\mathrm{a}}$ & $0.98^{\mathrm{a}}$ & $0.70^{\mathrm{b}}$ \\
\hline APX & $2.40^{\mathrm{b}}$ & $2.26^{\mathrm{bc}}$ & $1.88^{\mathrm{c}}$ & $2.48^{\mathrm{b}}$ & $3.12^{\mathrm{a}}$ \\
\hline $\mathrm{AO}$ & $0.46^{\mathrm{b}}$ & $0.52^{\mathrm{b}}$ & $1.28^{\mathrm{a}}$ & $1.36^{\mathrm{a}}$ & $1.51^{\mathrm{a}}$ \\
\hline
\end{tabular}

Note: I, young fruit stage; II, pre-white ripening stage; III, white ripening stage; IV, half-red ripening stage; V, full-red ripening stage. a, b and c mean the significant level at 5\%. Enzyme abbreviations are as defined in the legend to Fig. 2. 
noting that AsA-related enzymes, such as AO, APX, MDHAR, and DHAR are normally encoded by genes from multigene families, therefore choosing the key highly expressed genes should be considered in related studies.

\section{Conclusions}

In this research, we analyzed the accumulation dynamics of AsA during 'Jinsixiaozao' fruit development together with the gene expression profiling of AsA metabolism and the activity variations of related enzymes. $G L D H, A P X$ and MDHAR were considered as the key genes of jujube AsA synthesis, oxidization and recycling, respectively. These results provide useful new insights into the regulatory mechanisms of jujube AsA. However, more jujube cultivars need to be looked at to confirm these results in further studies.

Acknowledgements This work was supported by grants from the National Science and Technology Support Plan of China (2013BAD14B03), Agricultural University of Hebei Foundation for Leaders of Disciplines in Science Technology, Top-notch Talent Support Project of Hebei Province, and Youth Foundation of Hebei Educational Committee (QN2015232).

Compliance with ethics guidelines Yingying Chen, Zhihui Zhao, Jin Zhao, Mengjun Liu declare that they have no conflict of interest or financial conflicts to disclose.

This article does not contain any studies with human or animal subjects performed by any of the authors.

\section{References}

1. Veljovic-Jovanovic S D, Pignocchi C, Noctor G, Foyer C H. Low ascorbic acid in the vtcl mutant of Arabidopsis is associated with decreased growth and intracellular redistribution of the antioxidant system. Plant Physiology, 2001, 127(2): 426-435

2. Smirnoff N, Conklin P L, Loewus F A. Biosynthesis of ascorbic acid in plants: a renaissance. Annual Review of Plant Biology, 2001, 52 (1): 437-467

3. Zhang C, Liu J, Zhang Y, Cai X, Gong P, Zhang J, Wang T, Ye Z. Over expression of SlGMEs leads to ascorbate accumulation with enhanced oxidative stress, cold, and salt tolerance in tomato. Plant Cell Reports, 2011, 30(3): 389-398

4. Barth C, De T M, Conklin P. The role of ascorbic acid in the control of flowering time and the onset of senescence. Journal of Experimental Botany, 2006, 57(8): 1657-1665

5. De Tullio M C, Liso R, Arrigoni O. Ascorbic acid oxidase: an enzyme in search of a role. Biologia Plantarum, 2004, 48(2): 161166

6. Davey M W, Montagu M V, Inzé D, Sanmartin M, Kanellis A, Smirnoff N,Benzie I J J, Strain J J, Favell D, Fletcher J. Plant Lascorbic acid: chemistry, function, metabolism, bioavailability and effects of processing. Journal of the Science of Food and Agriculture, 2000, 80(7): 825-860

7. Gao Y R. Analysis of vitamins in Chinese jujube and wild jujube with high-performance liquid chromatography. Hebei: Agricultural University of Hebei, 2011 (in Chinese)

8. Wheeler G L, Jones M A, Smirnoff N. The biosynthetic pathway of vitamin C in higher plants. Nature, 1998, 393(6683): 365-369

9. Wolucka B A, Van Montagu M. GDP-mannose-3', 5'-epimerase forms GDP-L-gulose, a putative intermediate for the de novo biosynthesis of vitamin C in plants. Journal of Biological Chemistry, 2003, 278(48): 47483-47490

10. Agius F, González-Lamothe R, Caballero J L, Muñoz-Blanco J, Botella M A, Valpuesta V. Engineering increased vitamin C levels in plants by overexpression of a D-galacturonic acid reductase. Nature Biotechnology, 2003, 21(2): 177-181

11. Lorence A, Chevone B I, Mendes P, Nessler C L. Myo-inositol oxygenase offers a possible entry point into plant ascorbate biosynthesis. Plant Physiology, 2004, 134(3): 1200-1205

12. Dowdle J, Ishikawa T, Gatzek S, Rolinski S, Smirnoff N. Two genes in Arabidopsis thaliana encoding GDP-L-galactose phosphorylase are required for ascorbate biosynthesis and seedling viability. Plant Journal, 2007, 52(4): 673-689

13. Imai T, Ban Y, Terakami S, Yamamoto T, Moriguchi T. L-ascorbate biosynthesis in peach: Cloning of six L-galactose pathway related genes and their expression during peach fruit development. Physiologia Plantarum, 2009, 136(2): 139-149

14. Li M, Ma F, Guo C, Liu J. Ascorbic acid formation and profiling of genes expressed in its synthesis and recycling in apple leaves of different ages. Plant Physiology and Biochemistry, 2010, 48(4): 216-224

15. Bulley S, Wright M, Rommens C, Yan H, Rassam M, Lin-Wang K, Andre C, Brewster D, Karunairetnam S, Allan A C, Laing W A. Enhancing ascorbate in fruits and tubers through over-expression of the L-galactose pathway gene GDP-L-galactose phosphorylase. Plant Biotechnology Journal, 2012, 10(4): 390-397

16. Bulley S M, Rassam M, Hoser D, Otto W, Schünemann N, Wright M, MacRae E, Gleave A, Laing W. Gene expression studies in kiwifruit and gene over-expression in Arabidopsis indicates that GDP-L-galactose guanyltransferase is a major control point of vitamin C biosynthesis. Journal of Experimental Botany, 2009, 60 (3): 765-778

17. Li M J, Ma F W, Zhang M, Pu F. Distribution and metabolism of ascorbic acid in apple fruits (Malus domestica Borkh cv Gala). Plant Science, 2008, 174(6): 606-612

18. Cruz-Rus E, Amaya I, Sánchez-Sevilla J F, Botella M A, Valpuesta $\mathrm{V}$. Regulation of L-ascorbic acid content in strawberry fruits. Journal of Experimental Botany, 2011, 62(12): 4191-4201

19. Liu M J, Zhao J, Cai Q L, Liu G C, Wang J R, Zhao Z H, Liu P, Dai L, Yan G J, Wang W J, Li X S, Chen Y, Sun Y D, Liu Z G, Lin M J, Xiao J, Chen Y Y, Li X F, Wu B, Ma Y, Jian J B, Yang W, Yuan Z, Sun X C, Wei Y L, Yu L L, Zhang C, Liao S G, He R J, Guang X M, Wang Z, Zhang Y Y, Luo L H. The complex jujube genome provides insights into fruit tree biology. Nature Communications, 2014, 5: 5315

20. Xu Q, Chen L, Ruan X, Chen D, Zhu A, Chen C, Bertrand D, Jiao W, Hao B, Lyon M P, Chen J, Gao S, Xing F, Lan H, Chang J, Ge X, Lei Y, Hu Q, Miao Y, Wang L, Xiao S, Biswas M K, Zeng W, Guo F, Cao H, Yang X, Xu X, Cheng Y, Xu J, Liu J, Luo O, Tang Z, Guo W, Kuang H, Zhang H, Roose M, Nagarajan N, Deng X X, Ruan Y. 
The draft genome of sweet orange (Citrus sinensis). Nature Genetics, 2013, 45(1): 59-66

21. Huang S, Ding J, Deng D, Tang W, Sun H, Liu D, Zhang L, Niu X, Zhang X, Meng M, Yu J, Liu J, Han Y, Shi W, Zhang D, Cao S, Wei Z, Cui Y, Xia Y, Zeng H, Bao K, Lin L, Min Y, Zhang H, Miao M, Tang X, Zhu Y, Sui Y, Li G, Sun H, Yue J, Sun J, Liu F, Zhou L, Lei L, Zheng X, Liu M, Huang L, Song J, Xu C, Li J, Ye K, Zhong S, Lu B, He G, Xiao F, Wang H, Zheng H, Fei Z, Liu Y. Draft genome of the kiwifruit Actinidia chinensis. Nature Communications, 2013, 4: 2640

22. Zhao J, Liu Z C, Dai L, Liu M J. Isolation of total RNA for different organs and tissues of Ziziphus jujuba Mill. Journal of Plant Genetic Resources, 2009, 10: 111-117 (in Chinese)

23. Sun H F, Meng Y P, Cui G M, Cao Q F, Li J, Liang A H. Selection of housekeeping genes for gene expression studies on the development of fruit bearing shoots in Chinese jujube (Ziziphus jujuba Mill). Molecular Biology Reports, 2009, 36(8): 21832190

24. Livak K J, Schmittgen T D. Analysis of relative gene expression data using Real-Time Quantitative PCR and the $2^{-\Delta \Delta \mathrm{C}_{\mathrm{T}}}$ method. Methods, 2001, 25(4): 402-408

25. An H M. Physiological mechanism of accumulating high level ascorbic acid and molecular cloning and expression of its key biosynthetic enyzme in Rosa roxburghii Tratt. Zhejiang: Zhejiang University, 2004 (in Chinese)

26. Esaka M, Hattori T, Fujisawa K, Sakajo S, Asahi T. Molecular cloning and nucleotide sequence of full-length cDNA for ascorbate oxidase from cultured pumpkin cells. European Journal of Biochemistry, 1990, 191(3): 537-541

27. De Pinto M C, Francis D, De Gara L. The redox state of the ascorbate-dehydroascorbate pair as a specific sensor of cell division in tobacco BY-2 cells. Protoplasma, 1999, 209(1-2): 90-97

28. Imai $\mathrm{T}$, Ban $\mathrm{Y}$, Terakami S, Yamamoto $\mathrm{T}$, Moriguchi $\mathrm{T}$. LAscorbate biosynthesis in peach: cloning of six L-galactose pathway-related genes and their expression during peach fruit development. Physiologia Plantarum, 2009, 136(2): 139-149

29. Gournas C, Papageorgiou I, Diallinas G. The nucleobase-ascorbate transporter (NAT) family: genomics, evolution, structure-function relationships and physiological role. Molecular BioSystems, 2008, 4 (5): 404-416

30. Bulley S M, Rassam M, Hoser D, Otto W, Schünemann N, Wright M, MacRae E, Gleave A, Laing W. Gene expression studies in kiwifruit and gene over-expression in Arabidopsis indicates that GDP-L-galactose guanyltransferase is a major control point of vitamin C biosynthesis. Journal of Experimental Botany, 2009, 60 (3): 765-778

31. Cruz-Rus E, Botella M A, Valpuesta V, Gomez-Jimenez M C. Analysis of genes involved in L-ascorbic acid biosynthesis during growth and ripening of grape berries. Journal of Plant Physiology, 2010, 167(9): 739-748

32. Ioannidi E, Kalamaki M S, Engineer C, Pateraki I, Alexandrou D, Mellidou I, Giovannonni J, Kanellis A K. Expression profiling of ascorbic acid-related genes during tomato fruit development and ripening and in response to stress conditions. Journal of Experimental Botany, 2009, 60(2): 663-678

33. Cruz-Rus E, Amaya I, Sánchez-Sevilla J F, Botella M A, Valpuesta $\mathrm{V}$. Regulation of L-ascorbic acid content in strawberry fruits. Journal of Experimental Botany, 2011, 62(12): 4191-4201

34. Lunde C, Baumann U, Shirley N J, Drew D P, Fincher G B. Gene structure and expression pattern analysis of three monodehydroascorbate reductase (MDHAR) genes in Physcomitrella patens: implications for the evolution of the MDHAR family in plants. Plant Molecular Biology, 2006, 60(2): 259-275

35. Alhagdow M, Mounet F, Gilbert L, Nunes-Nesi A, Garcia V, Just D, Petit J, Beauvoit B, Fernie A R, Rothan C, Baldet P. Silencing of the mitochondrial ascorbate synthesizing enzyme L-galactono-1,4lactone dehydrogenase affects plant and fruit development in tomato. Plant Physiology, 2007, 145(4): 1408-1422 